Carolien Thush is werkzaam bij de afdeling Clinical Psychological Science van de Universiteit Maastricht, Reinout Wiers is verbonden aan de afdeling Ontwikkelingspsychologie van de Universiteit van Amsterdam.

Correspondentieadres: C. Thush, Clinical Psychological Science, Universiteit Maastricht, Postbus 616, 6200 MD Maastricht E-mailadres: c.thush@psychology.unimaas.nl

Serie: Preventie

\title{
Een dubbele kijk op minder drinken. De invloed van expliciete en impliciete alcoholgerelateerde processen en vroege interventie bij jongeren
}

\section{A double perspective on drinking less: The influence of explicit and implicit cognitive processes and early intervention in adolescents}

\begin{abstract}
Alcohol use among Dutch adolescents is a serious problem. Dual process models of addiction state that both implicit and explicit cognitive processes influence (early) adolescent drinking behavior. Where implicit cognitive processes represent more automatic associative motivational processes, explicit cognitive processes are related to more deliberate thought processes. The relationship between alcohol-related cognition and adolescent alcohol use is assumed to be moderated by other factors, such as executive functioning and motivation. This implicates that different intervention methods might be effective for different subgroups of at-risk adolescents. The present paper discusses the current state of affairs in intervention research from a dual process perspective.
\end{abstract}

Inleiding

Alcoholgebruik onder Nederlandse jongeren is een serieus probleem. In vergelijking met volwassenen heeft een relatief groot deel van alle adolescenten (22\%) een probleem met alcohol (Van Dijck \& Knibbe, 2005). Al op vroege leeftijd drinken Nederlandse adolescenten vrij regelmatig: $30 \%$ van de jongeren onder 12 jaar rapporteert in de laatste maand gedronken te hebben. Dit aantal neemt toe naarmate men ouder wordt: $43 \%$ van de dertienjarigen, $62 \%$ van de veertienjarigen en $70 \%$ van de vijftienjarigen rapporteert in de afgelopen maand gedronken te hebben (Monshouwer, Van Dorsselaer, Gorter, Verdurmen, \& Vollebergh, 2004). Europees gezien zijn Nederlandse adolescenten 'topscoorders' als het gaat om binge drinken, het drinken van grote hoeveelheden alcohol op één avond of gelegenheid (Hibell et al., 2004). Binge drinken komt vooral vaak voor in het weekend (Monshouwer et al., 2004) en op vakantie (Van de Luitgaarden, Wiers, Knibbe, \& Boon, 2006). Mede hierdoor neemt het aantal alcohol- 
vergiftigingen onder twaalf- tot zeventienjarigen toe (Van Kleef \& Van der Lely, 2006).

Onderzoek heeft aangetoond dat alcoholmisbruik onder adolescenten de kans op ernstige gevolgen op korte termijn vergroot, bijvoorbeeld het hebben van gedwongen en onveilige seks, voortijdig schoolverlaten, jeugdwerkeloosheid, sociale isolatie en depressie (Newcomb \& Bentler, 1989). Daarnaast heeft alcoholmisbruik tijdens de adolescentie ook een aantal zeer negatieve langetermijneffecten. Onderzoek heeft laten zien, dat het op jonge leeftijd beginnen met drinken van alcohol latere problemen met alcohol in sterke mate voorspelt (Grant \& Dawson, 1997). Bovendien wijst dierexperimenteel onderzoek uit dat de langetermijneffecten van binge drinken op het adolescent brein verschillen en veel ernstiger zijn dan de effecten op het volwassen brein (Crews, Braun, Hoplight, Switzer, \& Knapp, 2000; White, Ghia, Levin, \& Swartzwelder, 2000; White \& Swartzwelder, 2004). Studies met adolescenten laten zien dat alcoholmisbruik negatieve gevolgen heeft voor de ontwikkeling en het volgroeien van verschillende hersengebieden (DeBellis et al., 2000), verminderd neuropsychologisch functioneren veroorzaakt (Brown, Tapert, Granholm, \& Dellis, 2000) en leidt tot het moeten aanspreken van andere processen in executieve functietaken (Tapert et al., 2004).

Zodoende lijkt het erop dat adolescenten gevoeliger zijn voor de schadelijke effecten van alcohol op het brein dan volwassenen. Deze schadelijke effecten van alcohol manifesteren zich vooral ook in die hersengebieden die een rol spelen bij impulscontrole en dus een belangrijke rol zouden kunnen spelen in het voorkomen van bijvoorbeeld binge drinken (Spear, 2004).

Dit alles laat duidelijk zien dat de adolescentie een belangrijke periode is om schadelijk drinkgedrag te proberen terug te dringen. Niet in de laatste plaats omdat een sterke basis voor verslaving gevonden kan worden in de adolescentie (Grant \& Dawson, 1997). Naast een beter overheidsbeleid op het gebied van alcoholpreventie en het in ogenschouw nemen van de sociale context waarin adolescenten leven (Van de Luitgaarden, Thush, Wiers, \& Knibbe, 2008) is het cruciaal om ook binnen het individu te kijken naar bijvoorbeeld cognitieve kwetsbaarheidfactoren die een rol spelen in adolescent drinkgedrag. Onderzoek naar deze factoren kan nieuwe theoretische inzichten met zich meebrengen: wanneer, waarom en hoe schadelijk drinkgedrag zich ontwikkelt onder jongeren. Daarnaast kan onderzoek op dit terrein klinische implicaties hebben voor het ontwikkelen van secundaire of gerichte interventieprogramma's om schadelijk alcoholgebruik onder jongeren terug te dringen. Dit artikel zal zich dan ook voornamelijk richten op het bespreken van cognitieve kwetsbaarheidfactoren binnen het individu, die een rol spelen in adolescent drinkgedrag en op interventies die zich op deze processen richten.

\section{Adolescent alcoholgebruik \& cognitieve processen}

Traditionele cognitieve modellen, zoals de Theory of Planned Behavior (Ajzen, 1991), verklaren het bestaan van ongezond gedrag (zoals alcoholmisbruik) door de invloed van vertekende subjectieve normen, attitudes en waargenomen self-efficacy op de intentie om gedrag te veranderen in het rationele beslissingsproces. Echter, deze modellen hebben moeite met het verklaren waarom bijvoorbeeld adolescenten overmatig alcohol blijven gebruiken, zelfs als ze op de hoogte zijn van de schadelijke gevolgen voor hun gezondheid en sociale omgeving. Het lijkt erop dat ongezond gedrag, bijvoorbeeld overmatig alcoholgebruik, niet altijd verklaard kan worden als een rationele keuze waarbij men de voor- en nadelen tegen elkaar afweegt.

Op basis van duale procesmodellen van verslaving (bijvoorbeeld Stacy, Ames \& Knowlton, 2004; Wiers et al, 2007; zie Figuur 1) wordt inderdaad verondersteld dat niet alleen rationele expliciete cognitieve processen maar ook meer automatische impliciete cognitieve processen een rol spelen in het bepalen van het drinkgedrag in de (vroege) adolescentie. Waar impliciete cognitieve processen meer automatische associatieve motivationele processen representeren, zijn expliciete cognitieve processen meer gerelateerd aan doelbewuste denkprocessen (Greenwald \& Banaji, 1995; Kahneman, 2003; Strack \& Deutsch, 2004). Een voorbeeld van een impliciet cognitief proces is dat door eerdere ervaringen een bepaalde situatie (bijvoorbeeld 'je vrolijk voelen') een associatie met alcohol oproept en automatisch maakt dat je zin hebt in een drankje. Een voorbeeld van een expliciet cognitief proces is dat een doelbewuste reden of verwachting (bijvoorbeeld 'als ik alcohol drink, voel ik me meer ontspannen') maakt dat je van plan bent alcohol te gaan drinken om een bepaald doel of effect te bereiken. Onderzoek heeft laten zien dat drinkgedrag onder adolescenten voornamelijk wordt bepaald door impliciete positieve-arousal associaties met alcohol en negatieve alcoholverwachtingen (Thush \& Wiers, 2007; Thush, Wiers, Ames et al., 2007). Dit kan er bijvoorbeeld toe leiden dat op een feestje, de directe positieve-arousal effecten van alcohol ('vrolijk') als relatief automatische alcoholassociaties het drinkgedrag van een adolescent bepalen, terwijl meer indirecte negatieve effecten van alcohol ('als ik 


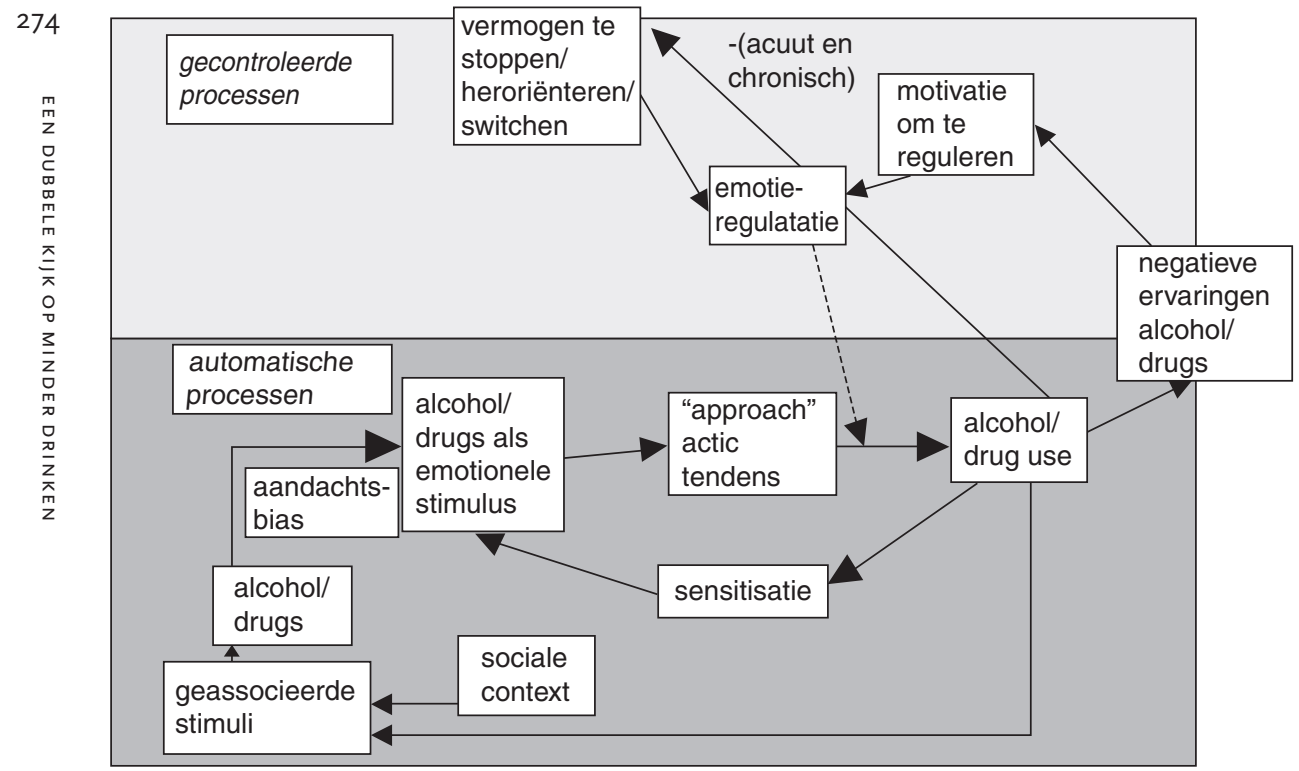

Figuur 1. Duale procesmodel van drinken onder adolescenten door Wiers et al (2007).

teveel alcohol drink, ben ik morgen misselijk') meer tijd, moeite en reflectie vereisen om gedrag te beïnvloeden.

Echter, deze duale procesmodellen van verslaving (Stacy et al., 2004; Wiers et al., 2007) veronderstellen dat meer doelbewuste expliciete cognitieve processen de invloed van impliciete appetitieve cognitieve processen zouden kunnen beteugelen, wanneer de persoon gemotiveerd genoeg is en genoeg controle (mate van executief functioneren) heeft om dit te doen. Neurobiologisch onderzoek naar verslaving heeft inderdaad aangetoond dat hersengebieden die betrokken zijn bij het nemen van doelbewuste beslissingen ook een rol spelen bij het modereren van impulsen om middelen te gebruiken (Bechara, 2005; Kalivas \& Volkow, 2005; Wilson, Sayette \& Fiez, 2004).

Het is dus van belang dat adolescenten naast motivatie om hun alcoholgebruik te matigen ook voldoende executieve controle bezitten. Executieve functies kunnen worden omschreven als een groep cognitieve vaardigheden, zoals shiften, inhiberen en updaten, die nodig zijn voor doelbewust en doelgericht gedrag (Miyake et al., 2000). De relatie tussen executieve functies en alcoholgebruik is tweeledig. Verminderd executief functioneren wordt gezien als een risicofactor om verslavend drinkgedrag te ontwikkelen (bijvoorbeeld Finn \& Hall, 2004; Peterson, Finn \& Pihl, 1992; Tapert, Baratta, Abrantes \& Brown, 2002). Daarnaast is aangetoond dat alcoholmisbruik negatieve gevolgen heeft voor het neuropsychologisch functioneren en de ontwikkeling van verschillende hersengebieden (DeBel- lis et al., 2000; Brown et al., 2000; Tapert et al., 2004). Verminderde executieve functies kunnen op hun beurt leiden tot minder doelbewuste controle en meer automatisch geactiveerd gedrag (Feldman-Barrett, Tugade, \& Engle, 2004).

In een studie door Thush et al (2008) werd inderdaad aangetoond dat adolescenten met een lager niveau van executief functioneren hun drinkgedrag in grote mate laten bepalen door impliciete alcoholgerelateerde processen, terwijl adolescenten met een hoger niveau van executief functioneren hun drinkgedrag voornamelijk door expliciete alcoholgerelateerde processen laten bepalen. Deze resultaten komen overeen met ander onderzoek naar het modererende effect van executieve functies op impliciete cognitieve processen. Het is aangetoond dat impliciet cognitief gedrag vooral voorspelt in personen met een relatieve lage werkgeheugencapaciteit of attentionele controle (Grenard et al, 2008; Payne, 2005).

Daarnaast komen onze bevindingen overeen met de eerdere bevinding van Tapert, McCarthy, Aarons, Schweinsburg en Brown (2003), dat expliciete positieve alcoholverwachtingen (zoals 'als ik alcohol drink, voel ik mij vrolijk') vooral alcoholgebruik in probleemdrinkende adolescenten met goede verbale vaardigheden voorspelden, terwijl dit bij probleemdrinkende adolescenten met slechte verbale vaardigheden niet het geval was. Verbale vaardigheden zijn nodig voor het ontwikkelen van het vermogen om in zichzelf te kunnen redeneren (Luria, 1961). Beide resultaten geven aan dat 
alcoholverwachtingen een diepe verwerking nodig hebben om het maken van beslissingen en het drinkgedrag wat daaruit volgt te beïnvloeden.

Deze resultaten en het feit dat zowel impliciete als expliciete cognitieve processen een uniek deel van het prospectieve drinkgedrag bepalen laten zien dat impliciete en expliciete cognitieve processen drinkgedrag beïnvloeden via verschillende wegen (zie Wiers \& Stacy, 2006). Kortom, zowel de invloed van impliciete als expliciete cognitieve processen en de interactie tussen werkgeheugencapaciteit en deze processen zouden in ogenschouw moeten worden genomen bij de ontwikkeling van preventie- en interventiemethodes.

Maar zelfs als iemand een hoog niveau van executief functioneren heeft, zal men nog steeds gemotiveerd moeten zijn of een doel voor ogen moeten hebben om deze executieve controle toe te passen (FeldmanBarrett et al., 2004; Wiers et al, 2007). Eerder onderzoek heeft laten zien dat de invloed van impliciete processen op gedrag toeneemt als de motivatie om niet te handelen naar deze automatische associaties laag is (Olson \& Fazio, 2004). Daarnaast is het belang van voldoende motivatie om drinkgedrag te veranderen al eerder aangetoond door een groot aantal studies (Milner \& Rollnick, 2002). Onderzoek laat zien dat drinkers met meer adaptieve motivationele structuren (positieve levensdoelen en optimistisch zijn over het bereiken van deze doelen) beter in staat zijn hun drinkgedrag in de hand te houden dan drinkers die deze motivationele structuren niet hebben. Bovendien heeft onderzoek aangetoond dat probleemdrinkers met adaptieve motivationele structuren een betere reactie vertonen op behandeling dan probleemdrinkers met maladaptieve motivationele structuren (Cox \& Klinger, 2002).

Samenvattend lijkt drinkgedrag onder adolescenten voornamelijk te worden bepaald door impliciete positieve-arousal associaties met alcohol en negatieve alcoholverwachtingen (Thush \& Wiers, 2007; Thush, Wiers, Ames et al., 2007). Deze doelbewuste expliciete cognitieve processen kunnen de invloed van deze impliciete appetitieve cognitieve processen beteugelen, maar alleen wanneer de persoon gemotiveerd genoeg is en genoeg executieve controle bezit (Stacy et al., 2004; Wiers et al., 2007). Ongezond gedrag, zoals overmatig alcoholgebruik, kan dus niet altijd verklaard worden als een rationele keuze waarbij men uitvoerig de voor- en nadelen tegen elkaar heeft afgewogen. Het is daarom zinvol om vanuit alternatieve duale procesmodellen van verslaving te kijken naar bestaande interventies om alcoholgebruik onder jongeren te matigen.

\section{Alcoholgebruik \& bestaande interventies}

Universele versus gerichte preventie

In Nederland wordt universele preventie in de vorm van alcohol- en drugsvoorlichting gestimuleerd en gesubsidieerd door de Nederlandse regering. Grote mediacampagnes zoals 'Drank maakt meer kapot dan je lief is' overspoelen sinds de jaren ' 80 ons land. Hoewel deze campagnes erg bekend zijn onder het Nederlandse publiek, blijken ze geen enkele aantoonbare invloed te hebben gehad op het matigen van alcoholgebruik (Van Dalen, 1999). Een ander voorbeeld van een voorlichtingscampagne, maar dan binnen de schoolomgeving, is 'De gezonde school en genotmiddelen'. Dit programma liet slechts kleine positieve veranderingen in het alcoholgebruik zien en zelfs een toename in de frequentie van het roken van marihuana onder gebruikers. Hoewel deze resultaten niet echt bemoedigend zijn, wordt geschat dat dit preventieprogramma elk jaar tenminste 350.000 middelbare school scholieren (tussen de 12 en 18 jaar) wordt aangeboden (Cuijpers, Jonkers, De Weerdt, \& De Jong, 2002). Ondanks dat universele preventie soms positieve effecten laat zien door uitstel van het beginnen met drinken tijdens de adolescentie (bijvoorbeeld Botvin, Griffin, Diaz, \& Ifill-Williams, 2001; Botvin \& Griffin, 2004), laten verschillende reviews zien dat universele preventie programma's over het algemeen niet erg effectief zijn (Foxcroft, Ireland, Lister- Sharp, Lowe \& Breen, 2003). $\mathrm{Er}$ is om die reden een aanvullende noodzaak om effectieve gerichte preventieprogramma's te ontwikkelen voor jongeren die, ongeacht alle universele voorlichting, toch overmatig alcohol gebruiken.

Ondanks dat door onderzoek belangrijke inzichten zijn verkregen over de gevolgen van alcoholgebruik onder adolescenten en risicofactoren voor het ontwikkelen van een alcoholprobleem, blijft het onduidelijk waar een effectieve gerichte interventie uit zou moeten bestaan om alcoholgebruik onder deze groep risicojongeren te matigen. Allereerst, heeft onderzoek zich in het verleden vooral gericht op de ontwikkeling van effectieve interventieprogramma's voor (jong)volwassenen en niet zozeer op adolescenten. Ten tweede, volgt vanuit het duale procesperspectief op verslaving de klinische implicatie dat gerichte interventies succesvoller kunnen worden in het matigen van alcoholgebruik door in deze programma's zowel de aandacht op het veranderen van impliciete als expliciete alcoholgerelateerde cognitie te richten. Verder zouden interventies effectiever kunnen zijn wanneer ook aandacht wordt besteed aan het verbeteren van executieve controle en het versterken van motivatie om te verande- 
ren. Hoewel fundamenteel onderzoek heeft laten zien dat al deze factoren van belang zijn bij de ontwikkeling van verslavend gedrag (bijvoorbeeld. Stacy et al., 2004; Wiers et al, 2007), is er nog steeds weinig bekend over de onderliggende relaties tussen deze factoren en hoe deze kennis gebruikt kan worden bij het ontwikkelen van interventies voor groepen (risico)jongeren.

\section{Langdurige gerichte interventie.}

Bij volwassenen die op zoek zijn naar hulp, bleken lange intensieve interventies effectiever te zijn dan kortdurende interventies (Moyer, Finney, Swearingen, \& Vergun, 2002). Een gerelateerd onderzoek onder Nederlandse risicojongeren, die hun overmatig alcoholgebruik wilden matigen, is een studie van Thush, Wiers, Theunissen et al (2007). In deze studie werd de effectiviteit van een relatief lang programma (althans in preventietermen), gericht op het veranderen van expliciete cognitieve processen bij risicojongeren, onderzocht in een gerandomiseerd klinische trial. Deze interventie bestond uit zeven sessies waarin interventiemethoden gecombineerd werden die in het verleden effectief bleken te zijn in het reduceren van alcoholgebruik in jongvolwassenen. Er werd gebruik gemaakt van cognitieve gedragstraining en motivationele feedback (gebaseerd op programma's van Fromme, Marlatt, Baer \& Kivlahan, 1994 en Dimeff, Bear, Kivlahan \& Marlatt, 1999) en van een Expectancy Challenge (EC; Darkes \& Goldman, 1993). In een Expectancy Challenge (Darkes \& Goldman, 1993) wordt geprobeerd overmatig alcoholgebruik terug te dringen door de positieve verwachtingen die jongeren hebben ten aanzien van alcohol te ontkrachten (bijvoorbeeld de verwachting dat je van alcohol energiek, assertief of socialer wordt). In Nederland heeft deze interventie al eerder bescheiden positieve resultaten laten zien in het matigen van alcoholgebruik onder studenten (mannen en vrouwen) en bij jonge mannen op vakantie (Wiers, Van de Luitgaarden, Van den Wildenberg, \& Smulders, 2005, Van de Luitgaarden, Wiers, Knibbe, \& Candel, 2007).

Daarnaast bevatte deze interventie een nieuw element: de biologische, cognitieve en sociale risicofactoren voor het ontwikkelen van een alcoholprobleem werden besproken. De interventie was effectief in het veranderen van verschillende beoogde cognitieve determinanten: er was een significante toename in de perceptie van risicofactoren voor het ontwikkelen van een alcoholprobleem en een significante afname in positieve alcoholverwachtingen voor een hoge dosis alcohol in de experimentele groep in vergelijking tot de controlegroep. Echter, ondanks deze veranderingen in de cognitieve determinanten van drinkgedrag, ver- toonde de experimentele groep geen significant verschil in de afname van drinken op posttest in vergelijking tot de controlegroep. De resultaten laten geen langetermijneffect van de interventie zien. Dus, hoewel de interventie er in slaagde expliciete alcoholgerelateerde cognitie te veranderen, bleef de relatieve afname in drankgebruik ten opzichte van de controlegroep uit.

Dat de verwachte verandering in gedrag niet kon worden waargenomen, kan te wijten zijn aan dat het focussen op voornamelijk deze cognitieve determinanten niet genoeg is om verandering in gedrag bij risicojongeren te bewerkstelligen. Hoewel cognitieve gedragstraining en motivationele feedback in het verleden effectief zijn gebleken in het terugdringen van overmatig alcoholgebruik in de populatie van jongvolwassenen (Larimer \& Cronce, 2002; 2007), kunnen deze strategieën minder effectief zijn in een populatie van risicojongeren. De verminderde effectiviteit in deze populatie kan worden verklaard uit het feit dat adolescenten een andere reactie op alcohol vertonen dan volwassenen. Adolescenten ervaren niet zozeer de negatieve effecten, maar meer de positieve-arousal effecten van het drinken van alcohol (NIAAA, 2005). Daardoor kan het zijn dat adolescenten vinden dan ze niet genoeg reden hebben om hun drinkgedrag te veranderen. Bovendien kunnen deze interventiestrategieën minder effectief zijn in deze populatie van risicojongeren, omdat adolescent drinkgedrag mogelijk in grotere mate wordt beïnvloed door andere processen dan door expliciete cognitieve processen. De relatie tussen alcoholgerelateerde cognitie en adolescent alcoholgebruik wordt geacht te worden gemodereerd door andere factoren, zoals executief functioneren en motivatie.

\section{Kortdurende gerichte interventie} Onder volwassenen die niet op zoek zijn naar hulp, blijken kortdurende interventies vaak al enorm effectief te zijn in het verminderen van alcoholgebruik (Moyer et al., 2002). Onderzoek naar deze kortdurende interventies, die motivatie om te veranderen proberen te versterken door gebruik te maken van Motivational Interviewing (MI; Miller \& Rollnick, 2002), heeft laten zien dat ze effectiever zijn in het matigen van alcoholgebruik onder volwassenen dan interventies waarbij alleen informatie of voorlichting werd gegeven (bijvoorbeeld Marlatt et al., 1998; voor een review zie Larimer \& Cronce, 2002; 2007). Deze korte motivationele interventies zouden in het bijzonder veelbelovend kunnen zijn onder risicogroepen die geen hulp of behandeling zoeken (Grenard, Ames, Wiers, Thush, Stacy et al., 2007; Moyer et al., 2002). Er is tot dusver echter slechts weinig bewijs voor 
de effectiviteit van $\mathrm{MI}$ onder risicojongeren, hoewel daarbij moet worden aangetekend dat er momenteel nog niet veel onderzoek onder deze groep gedaan is (voor een review zie Grenard, Ames, Pentz \& Sussman, 2006).

Daarnaast is echter nog niet veel bekend over de onderliggende cognitieve processen die MI-effecten kunnen verklaren. Tijdens een MI-sessie worden verschillende counselingtechnieken gebruikt (zoals reflectief luisteren, bekrachtigen, open vragen stellen en het geven van samenvattingen) om zogenaamde 'change talk' teweeg te brengen (Miller \& Rollnick, 2002). Dit creëert een situatie waarin kan worden gepraat en nagedacht over het eigen gedrag (ook in vergelijking met anderen), specifieke risicosituaties en de voor- en nadelen van het drinkgedrag van de cliënt. Het doel is om het nadenken over het eigen gebruik te stimuleren, waardoor mogelijkerwijs het drinkgedrag zal veranderen. Het verhogen van de motivatie om te veranderen wordt gezien als één van de belangrijkste factoren om een verandering in gedrag te bewerkstelligen (Miller \& Rollnick, 2002). Een toename in de motivatie om te veranderen zou dus een belangrijk onderliggende verklaring kunnen zijn waarom MI werkt. Desondanks zijn er slecht een paar studies met gemixte resultaten, die hebben geprobeerd de onderliggende cognitieve processen van MI bloot te leggen (Bosari \& Carey, 2000; Wood, Capone, Laforge, Erickson \& Brand, 2007).

Een voorbeeld van onderzoek onder risicojongeren, dat onderliggende cognitieve processen van MI probeert te analyseren, is een studie van Thush et al. (in press). In deze gerandomiseerde klinische trial werd onderzocht wat de invloed van één sessie Motivationeel Interviewen (MI) is op impliciete en expliciete alcoholgerelateerde cognitie en alcoholgebruik in risicojongeren. Geredeneerd vanuit duale procesmodellen van verslaving (Stacy et al., 2004; Wiers et al, 2007), zou ingrijpen op het niveau van motivatie en/of doelbewuste expliciete redenen om te drinken moeten leiden tot een verandering van drinkgedrag. Door de motivatie om te veranderen te verhogen zouden jongeren beter in staat moeten kunnen zijn om negatieve alcoholverwachtingen op te roepen en daarmee de invloed van impliciete appetitieve processen op drankgebruik te matigen. Desondanks vonden de onderzoekers geen bewijs dat de huidige Ml-interventie motivatie om te veranderen of drinkgedrag beïnvloedde, hoewel MI over het algemeen wordt verondersteld de bereidheid om te veranderen te vergroten en dit weer sterk verband houdt met het veranderen van gedrag (Miller \& Rollnick, 2002). Gezien het feit dat er geen aanwijzingen waren dat de MI-interventie op enige wijze niet in overeenstemming met de Ml-principes is uitgevoerd, werpen deze bevindingen een aantal vragen op over de bruikbaarheid van MI binnen deze specifieke populatie van risicojongeren en de mechanismen waardoor MI mogelijkerwijs werkt. Toekomstig experimenteel onderzoek naar de invloed van MI op alcoholgerelateerde cognitie kan mogelijk antwoorden geven op deze vragen.

\section{Alcoholgebruik \& toekomstige interventies}

Hoewel we weten dat impliciete cognitieve processen naast expliciete processen in belangrijke mate drinkgedrag onder jongeren bepalen (Ames, Sussman, Dent \& Stacy, 2007; Stacy, Ames, Sussman, \& Dent, 1996; Stacy, 1997; Thush \& Wiers, 2007; Thush, Wiers, Ames et al., 2007; Thush et al., 2008), is het nog onduidelijk hoe deze impliciete associaties worden gevormd en hoe de invloed van deze processen kan worden veranderd of ingeperkt. Deze kennis is cruciaal voor het ontwikkelen van effectieve preventie die ook op meer impliciete automatische processen inspeelt.

\section{Ontwikkeling van impliciete alcoholgerelateerde cognitie}

Tot dusver zijn er slecht enkele wetenschappelijk pogingen geweest om de ontwikkeling van impliciete alcoholgerelateerde cognities in een vroeg stadium in kaart te brengen (O'Connor, Fite, Nowlin, \& Colder, 2007; Thush \& Wiers, 2007). Jongeren in een vroeg stadium van de adolescentie, die nog niet lang directe ervaringen hebben met alcohol, associëren alcohol steeds meer met positieve, arousal-gerelateerde en minder negatieve effecten naarmate ze ouder worden en meer gaan drinken (Thush \& Wiers, 2007). Bovendien hebben kinderen al sterke impliciete positieve associaties met alcohol, voordat ze zelf enige directe ervaring hebben met het drinken van alcohol en expliciet erg negatief waren over alcohol (O'Connor et al, 2007). Dit wijst erop dat kinderen al in een vroeg stadium indirect uit de wereld om hen heen leren alcohol met positieve effecten te associëren.

Het ontbreekt momenteel aan experimenteel onderzoek dat de factoren kan aanwijzen die belangrijk zijn bij de ontwikkeling van deze impliciete positieve associaties met alcohol. Het kan bijvoorbeeld zo zijn dat niet alleen de mate van executieve controle en motivatie om te veranderen bepalen hoeveel impact impliciete associaties hebben op drinkgedrag, maar dat deze factoren ook belangrijk zijn bij de vorming van deze impliciete associaties. Het wordt bijvoorbeeld verondersteld dat de mate van associatief leren beperkt kan worden door 
het verwerken van informatie met een bepaald doel voor ogen, oftewel top-down processing (De Houwer, Baeyens $\&$ Field, 2005). Kinderen met een relatief laag niveau van executieve controle en zonder een duidelijk doel of motivatie kunnen worden gekenmerkt door mindere top-down processing.

Daarnaast kunnen ook andere factoren een rol spelen bij de vorming van deze impliciete positieve associaties met alcohol, zoals de sociale context. Kinderen leren associaties met alcohol indirect door naar anderen te kijken. Eerder onderzoek heeft al laten zien dat kinderen van alcoholisten eerder beginnen met drinken en een grotere kans lopen om een alcoholprobleem te ontwikkelen (bijvoorbeeld Hill, Shen, Lowers, \& Locke, 2000). Deels kan dit verklaard worden door een genetische overerfbare biochemische reactie op alcohol (Schuckit, 1998), maar deze relatie wordt ook gemedieerd door hoe vaak men blootgesteld is aan een overmatig drinkende ouder (Brown, Tate, Vik, Haas, \& Aarons, 1999). Echter, de sociale leertheorie stelt daarnaast ook dat observationeel leren wordt vergemakkelijkt als de gelijkenis tussen degene die observeert en degene die geobserveerd wordt hoog is (Bandura, 1977). Dit kan vooral steeds belangrijker worden tijdens de voortschrijdende adolescentie, aangezien jongeren steeds gevoeliger worden voor de invloed van leeftijdsgenoten met een piek rond zestien jaar (Gardner \& Steinberg, 2005).

Toekomstig onderzoek zal moeten uitwijzen onder welke sociale omstandigheden impliciete alcoholgerelateerde associaties worden gevormd (in longitudinale en meer experimentele designs). Deze kennis kan dan worden ingezet in de ontwikkeling van preventie campagnes door ook bijvoorbeeld negatieve associaties met alcohol of positieve associaties met nietalcoholische dranken aan te leren.

Veranderen van impliciete alcoholgerelateerde cognitie Daarnaast is het belangrijk dat we meer inzicht krijgen in hoe we de invloed van deze impliciete alcoholgerelateerde associaties kunnen veranderen of beperken. Uit alcoholonderzoek blijkt dat verschillende interventiemethodes effectief kunnen zijn voor verschillende subgroepen van risicojongeren (Grenard et al, 2008; Thush et al., 2008) Risicojongeren met een relatief goede werkgeheugencapaciteit worden meer beïnvloed door expliciete processen en lijken dus, vanuit het duale procesmodel van verslaving, gebaat bij interventies die de beschermende negatieve alcoholverwachtingen versterken. Bijvoorbeeld door een Motivationeel Interview, dat nog steeds een veelbelo- vende methode bij risicojongeren kan zijn (Grenard et al, 2007)

Onderzoek heeft laten zien dat negatieve alcoholverwachtingen als een beschermende factor kunnen fungeren bij volwassenen (Jones, Corbin, \& Fromme, 2001; Jones \& McMahon, 1996) en jongeren (Thush \& Wiers, 2007). Toch zal moeten worden bezien of alleen het versterken van negatieve alcoholverwachtingen genoeg zal zijn om overmatig alcoholgebruik onder risicojongeren terug te dringen, helemaal aangezien jongeren nu eenmaal sterker de positieve-arousal effecten dan de negatieve effecten van alcohol ervaren (NIAAA, 2005).

Risicojongeren met een relatief slechte werkgeheugencapaciteit worden juist beïnvloed door meer impliciete processen en zouden dus gebaat zijn bij interventies die direct inspelen op hun automatische associaties of reacties op alcohol (bijvoorbeeld attentionele trainingen; zie Wiers et al., 2006) of interventies die tot doel hebben de executieve controle en impulsregulatie te versterken, zoals een werkgeheugentraining (Klingberg et al, 2005). Onderzoek heeft inderdaad laten zien dat executieve functies en de geassocieerde hersengebieden geen statische processen of structuren zijn, maar worden gekenmerkt door plasticiteit en kunnen worden veranderd door feedback en training (Erickson et al., 2007; Olesen, Westerberg \& Klingberg, 2004). Er is wat beginnend bewijs dat dit soort trainingsprocedures een effectieve directe interventie zijn voor kinderen gediagnosticeerd met ADHD (Klingberg, et al., 2005; Shalev, Tsal \& Mevorach, 2007). Toekomstig experimenteel onderzoek zal moeten uitwijzen of deze trainingen ook effectief zijn in het verbeteren van executieve controle in andere populaties en in andere leeftijdsgroepen. Daarnaast, zal in een klinische setting moeten worden bezien of deze trainingsmethodes een matigend effect kunnen hebben op de invloed van impliciete cognitieve processen op drinkgedrag.

Een mogelijke richting voor toekomstig onderzoek is het combineren van het verhogen van de executieve controle en motivatie in één interventie. Motivatie alleen is niet genoeg om executieve controle te hebben (Towles-Schwen \& Fazio, 2006), maar in staat zijn je impulsen te reguleren vereist ook nog steeds dat je gemotiveerd moet zijn om dit te doen (Feldman-Barrett et al., 2004; Wiers et al, 2007). Fadardi en Cox hebben laten zien dat de motivatie om te veranderen wordt versterkt als het vermogen om zichzelf te inhiberen toeneemt (in Wiers et al., 2006). Dit laat zien dat executieve controle en motivatie, twee factoren die verondersteld worden een modererende werking te hebben op 
impliciete processen, niet afzonderlijk maar juist gezamenlijke onderzocht dienen te worden.

\section{Conclusie}

Concluderend kunnen we zeggen, dat de adolescentie een periode is waarin er een verhoogde kwetsbaarheid is om zich bezig te houden met risicovolle activiteiten, zoals overmatig alcoholgebruik. Onderzoek heeft nieuwe inzichten gebracht met betrekking tot de cognitieve processen, die dit adolescent drinkgedrag mogelijkerwijs voeden. Zowel impliciete appetitieve associatieve alcoholgerelateerde processen als expliciete reflectieve alcoholgerelateerde processen beïnvloeden adolescent drinkgedrag. De directe positieve-arousal effecten van alcohol lijken op relatief automatische wijze drinkgedrag aan te sturen, terwijl meer indirecte negatieve effecten van drinken meer tijd, moeite en reflectie nodig lijken te hebben om drinkgedrag te kunnen beïnvloeden. Executief functioneren modereert deze relatie tussen alcoholgerelateerde cognitie en adolescent alcoholgebruik. Er is meer onderzoek nodig om vast te stellen of inderdaad expliciete reflectieve processen de invloed van impliciete appetitieve associatieve processen modereren, wanneer de persoon gemotiveerd genoeg is en voldoende executieve capaciteit heeft.

Dit impliceert dat verschillende interventiemethodes effectief kunnen zijn voor verschillende subgroepen van risicojongeren. Aan de ene kant lijken risicojongeren met een relatief goede werkgeheugencapaciteit gebaat bij interventies die de beschermende negatieve alcoholverwachtingen versterken. Bijvoorbeeld door een motivationeel interview, dat een veelbelovende methode bij risicojongeren lijkt te zijn (Grenard et al, 2007). Aan de andere kant zouden risicojongeren met een relatief slechte werkgeheugencapaciteit gebaat zijn bij interventies die direct inspelen op hun automatische associaties of reacties op alcohol (bijvoorbeeld attentionele trainingen; zie Wiers et al., 2006) of interventies die tot doel hebben de impulsregulatie te versterken, zoals een werkgeheugentraining, die succesvol is bij kinderen met ADHD (Klingberg et al, 2005).

Echter, het moet worden gezegd dat zelfs als de werkgeheugencapaciteit van deze risicojongeren kan worden verbeterd, dit nog niet het belang van motivatie en doelen uitvlakt (Feldman-Barrett, Tugade \& Engle, 2004; Wiers et al, 2007). Eerder onderzoek heeft laten zien dat deze twee factoren, die verondersteld worden een modererende werking te hebben op impliciete processen, niet afzonderlijk maar juist gezamenlijk onderzocht dienen te worden in verslavingsonderzoek en deel dienen uit te maken van interventieprogramma's.

Daarnaast is het nog onduidelijk hoe impliciete associaties met alcohol worden gevormd en hoe de invloed van deze processen kan worden veranderd of ingeperkt. Deze kennis is cruciaal voor het ontwikkelen van effectieve preventie die ook op meer impliciete automatische processen inspeelt. Toekomstig onderzoek zal moeten uitwijzen welke methodes als effectieve elementen kunnen worden opgenomen in interventieprogramma's.

Literatuur

Ames, S.L., Sussman, S., Dent, C.W., \& Stacy, A.W. (2005). Implicit cognition and dissociative experiences as predictors of adolescent substance use. American Journal of Drug Q Alcohol Abuse, 31, 129-162.

Azjen, I. (1991). The theory of planned behavior. Organizational Behavior and Human Decision Processes, 50, 179-221.

Bandura, A. (1977). Social learning theory. Englewood Cliffs: PrenticeHall.

Bechara, A. (2005). Decision making, impulse control and loss of willpower to resist drugs: A neurocognitive perspective. Nature Neuroscience, 8, 1459-1463.

Bosari, B. \& Carey, K.B. (2000). Effects of a brief motivational intervention with college student drinkers. Journal of Consulting and Clinical Psychology, 68, 728-733.

Botvin, G.J., Griffin, K.W. (2004). Life skills training: Empirical predictions and future directions. Journal of Primary Prevention, 25, 211-232.

Botvin, G.J., Griffin, K.W., Diaz, T., \& Ifill-Williams, M. (2001) Preventing binge drinking during early adolescence: One- and two-year follow-up of a school based preventive intervention. Psychology of Addictive Behavior, 15, 360-365.

Brown, S.A., Tapert, S.F., Granholm, E., \& Dellis, D.C. (2000). Neurocognitive functioning of adolescents: Effects of protracted alcohol use. Alcohol: Clinical and Experimental Research, 24, 164-171.

Brown, S.A., Tate, S.R., Vik, P.W., Haas, A.L., \& Aarons, G.A (1999). Modeling of alcohol use mediates the effect of family history of alcoholism on adolescent alcohol expectancies. Experimental and Clinical Psychopharmacology, 7, 20-27.

Cox, W.M., \& Klinger, E. (2002). Motivational structure relationships with substance use and processes of change. Addictive Behaviors, 27, $925-940$.

Crews, F.T., Braun, C.J, Hoplight, B., Switzer, R.C. $3^{\text {rd }}$, \& Knapp D.J. (2000). Binge ethanol consumption causes differential brain damage in young adolescent rats compared with adult rats. Alcoholism: Clinical and Experimental Research, 24, 1712-1723. 
Cuijpers, P., Jonkers, R., De Weerdt, I., \& De Jong, A. (2002). The effects of drug abuse prevention at school: The 'Healthy School and Drugs' project. Addiction, 97, 67-73.

Darkes, J., \& Goldman, M.S. (1993). Expectancy challenge and drinking reduction: Experimental evidence for a mediational process. Journal of Consulting and Clinical Psychology, 61, 344-353.

De Bellis, M.D., Clark, D.B., Beers, S.R., Soloff, P.H., Boring A.M., Hall, J. et al. (2000). Hippocampal volume in adolescent-onset alcohol use disorders. American Journal of Psychiatry, 157, 737-744.

De Houwer, J., Baeyens, F., \& Field, A.P. (2005). Associative learning of likes and dislikes: Some current controversies and possible ways forward. Cognition and Emotion, 19, 161- 174.

Dimeff, L.A., Bear, J.S., Kivlahan, D.R., \& Marlatt, G.A. (1999). BASICS: Brief Alcohol Screening and Intervention for College Students: A harm reduction approach. New York: Guilford Press.

Erickson, K.I, Colcombe, S.J., Wadhwa, R., Bhere, L., Peterson, M.S., Scalf, P.E., Kim, J.S., Alvarado, M., \& Kramer, A.F. (2007). Training-induced functional activation in dual task processing: An fMRI study. Cerebral Cortex. 17, $192-204$.

Feldman-Barrett, L.F., Tugade, M.M., \& Engle, R.W. (2004). Individual differences in working memory capacity and dual-process theories of the mind. Psychological Bulletin, 130, 553-573.

Finn, P.R., \& Hall, J. (2004). Cognitive ability and risk for alcoholism: Short-term memory capacity and intelligence moderate personality risk for alcohol problems. Journal of Abnormal Psychology, 113, 569-581.

Foxcroft, D.R., Ireland, D., Lister-Sharp, D.J, Lowe, G., \& Breen, R. (2003). Longer-term primary prevention for alcohol misuse in young people: a systematic review. Addiction, 98, 397-411.

Fromme, K., Marlatt, G.A., Baer, J.S., \& Kivlahan, D.R. (1994). The alcohol skills training program: Group intervention for young adult drinkers. Journal of Substance Abuse Treatment, 11, 143-154.

Gardner, M. \& Steinberg, L. (2005). Peer influence on risk taking, risk preference and risky decision making in adolescence and adulthood: An experimental study. Developmental Psychology, 41, $625-635$.

Grant, B.F., \& Dawson, D.A. (1997). Age at onset of alcohol use and its association with DSM-IV alcohol abuse and dependence: results from the national longitudinal alcohol epidemiologic survey. Journal of Substance Abuse, 9, 103-110.

Greenwald, A.G., \& Banaji, M.R. (1995). Implicit social cognition: Attitudes, self-esteem, and stereotypes. Psychological Review, 102, 4-27.

Grenard, J.L., Ames, S.L., Pentz, M.A., \& Sussman, S. (2006). Motivational interviewing with adolescents and young adults for drug-related problems. International Journal of Adolescent Medical Health, 18, $53-67$

Grenard, J.L., Ames, S.L., Wiers, R.W., Thush, C., Stacy, A.W., \& Sussman, S. (2007). Brief intervention for substance use among at-risk adolescents: An initial study. Journal of Adolescent Health, 40, 188-191.
Grenard, J.L., Ames, S.L, Wiers, R.W., Thush, C., Sussman, S., \& Stacy, A.W. (2008). Working memory moderates the predictive effects of drug-related associations on substance use. Psychology of Addictive Behaviors, 22, 426-432.

Hibell, B., Andersson, B., Bjarnason, T., Ahlström, S., Balakireva, O., Kokkevi, A., et al. (2004). The ESPAD report 2003: Alcohol and other drug use among students in 35 European countries. Stockholm: The Swedish Council for Information on Alcohol and Other Drugs (CAN) and the Pompidou Group at the Council of Europe.

Hill, S.Y., Shen, S., Lowers, L., \& Locke, J. (2000). Factors predicting the onset of adolescent drinking in families at high risk for developing alcoholism. Biological Psychiatry, 48, 265 -275.

Jones, B.T., Corbin, W. \& Fromme, K. (2001). A review of expectancy theory and alcohol consumption. Addiction, 91, 57-72.

Jones, B.T., \& McMahon, J. (1996). A comparison of positive and negative alcohol expectancy and value and their multiplicative composite as predictors of post- treatment abstinence survivorship. Addiction, 91, 89-99.

Kahneman, D. (2003). A perspective on judgment and choice. American Psychologist, 58, 697-720.

Kalivas, P.W., \& Volkow, N.D. (2005). The neural basis of addiction: A pathology of motivation and choice. American Journal of Psychiatry, 162, 1403-1413.

Klingberg, T., Fernell, E., Olesen, P.J., Johnsons, M., Gustafsson, P., Dahlström, K. Gillberg, C.G., Forssberg, H., \& Westerberg, L.P. (2005). Computerized training of working memory in children with ADHD: A randomized, controlled trial. Journal of the American Academy of Child and Adolescent Psychiatry, 44, 177- 186.

Larimer, M.E., \& Cronce, J.M. (2002). Identification, prevention and treatment: A review of individual-focused strategies to reduce problematic alcohol consumption by college students. Journal of Studies on Alcohol, 14 (Suppl 1), 148-163.

Larimer, M.E., \& Cronce, J.M. (2007). Identification, prevention and treatment revisited: Individual-focused college drinking prevention strategies 1999-2006. Addictive Behaviors, 32, 2439-2468.

Luria, A.R. (1961). The role of speech in the regulation of normal and abnormal behavior. New York: Liveright Publications.

Marlatt, G.A., Baer, J.S., Kivlahan, D.R., Dimeff, L.A., Larimer, M.E., Quigley, L.A. et al. (1998). Screening and brief intervention for high-risk college student drinkers: Results from a 2-year follow-up assessment. Journal of Consulting and Clinical Psycho$\log \rangle$, 66, 604-615.

Miller, W.R. \& Rollnick, S. (2002). Motivational Interviewing: Preparing people to change addictive behaviors (2nd ed.). New York: Guilford Press.

Miyake, A., Friedman, N.P., Emerson, M.J., Witzki, A.H., Howerter, A., \& Wager, T.D. (2000). The unity and diversity of executive functions and their contributions to complex "frontal lobe" tasks: A latent variable analysis. Cognitive Psychology, 41, 49-100. Monshouwer, K., Van Dorsselaer, S., Gorter, A., Verdurmen, J., \& Vollebergh, W. (2004). Jeugd en riskant gedrag. Kerngegevens uit 
het peilstationsonderzoek 2003. Roken, drinken, drugsgebruik en gokken onder scholieren vanaf tien jaar. Utrecht: Trimbos-instituut.

Moyer, A., Finney, J., Swearingen, C, \& Vergun, P. (2002). Brief interventions for alcohol problems: A meta-analytic review of controlled investigations in treatment-seeking and nontreatment-seeking populations. Addiction, 97, 279-92.

National Institute on Alcohol Abuse and Alcoholism (NIAAA) (2005). The effects of alcohol on physiological processes and biological development. Alcohol Research and Health, 28, 125-131.

Newcomb, M.D., \& Bentler, P.M. (1989). Substance use and abuse among children and teenagers. American Psychologist, 44, 242-248.

O'Conner, R.M ., Fite, P.J., Nowlin, P.R., \& Colder, C.R. (2007). Children's belief about substance use: An examination of age differences in implicit and explicit cognitive precursors of substance use initiations. Psychology of Addictive Behaviors, 21, 525533.

Olesen, P.J., Westerberg, H. \& Klingberg, T. (2004). Increased prefrontal and parietal activity after training of working memory. Nature Neuroscience, 7, 75-79.

Olson, M.A., \& Fazio, R.H. (2004). Trait interferences as a function of automatically activated racial attitudes and motivation to control prejudiced reactions. Basic Applied Social Psychology, 26, $1-11$

Peterson, J.B., Finn, P.R., \& Pihl, R.O. (1992). Cognitive dysfunction and the inherited predisposition to alcoholism. Journal of Studies on Alcohol, 53, 154-16o.

Payne, B.K. (2005). Conceptualizing control in social cognition: How executive functioning modulates the expression of automatic stereotyping. Journal of Personality and Social Psychology, 89, 488-503.

Schuckit, M.A. (1998). Biological, psychological and environmental predictors of the alcoholism risk: A longitudinal study. Journal of Studies on Alcohol, 59, 485-494.

Shalev, L., Tsal, Y., Mevorach, C. (2007). Computerized progressive attentional training (CPAT) program; Affective direct intervention for children with ADHD. Child Neuropsychology, 13, 382-388.

Spear, L.P. (2004). Adolescence and the trajectory of alcohol use: Introduction to part VI. Annals of the New York Academy of Sciences, 1021, $202-205$.

Stacy, A.W. (1997). Memory activation and expectancy as prospective predictors of alcohol and marijuana use. Journal of Abnormal Psychology, 106, 61-73.

Stacy, A.W., Ames, S.L., Sussman, S. \& Dent, C.W. (1996). Implicit cognition in adolescent drug use. Psychology of Addictive Behaviors, 10, 190-203

Stacy, A.W., Ames, S.L., \& Knowlton, B.J. (2004). Neurologically plausible distinctions in cognition relevant to drug use etiology and prevention. Substance Use and Misuse, 39, 1571-1623.

Strack, F., \& Deutsch, R. (2004). Reflective and impulsive determinants of social behavior. Personality and Social Psychology Review, $8,220-247$
Tapert, S.F., Baratta, B.S., Abrantes, B.A., \& Brown, S.A. (2002). Attention dysfunction predicts substance involvement in community youths. Journal of American Academy of Child and Adolescent Psychiatry, 41, 680-686.

Tapert, S.F., McCarthy, D.M., Aarons, G.A., Schweinsburg, A.D., \& Brown, S.A., (2003). Influence of language abilities and alcohol expectancies on the persistence of heavy drinking in youth. Journal of Studies on Alcohol, 64, 313-321.

Tapert, S.F., Schweinsburg, A.D., Barlett, V.C., Brown, S.A., Frank, L.R., Brown, G.G. et al. (2004). Blood oxygen level dependent response and spatial working memory in adolescents with alcohol use disorders. Alcoholism: Clinical and Experimental Research, 28, 1577-1586.

Thush, C. \& Wiers, R.W. (2007). Explicit and implicit alcohol-related cognitions and the prediction of future drinking in adolescents. Addictive Behaviors, 32, 1367-1383.

Thush, C., Wiers, R.W., Ames, S.L., Grenard, J.L., Sussman, S., \& Stacy, A.W. (2007). Apples and oranges? Comparing indirect measures of alcohol-related cognition predicting alcohol use in at-risk adolescents. Psychology of Addictive Behaviors, 21, 587-591.

Thush, C., Wiers, R.W. , Moerbeek, M., Ames, S.L., Grenard, J.L., Sussman, S., \& Stacy, A.W. (in press). The influence of Motivational Interviewing on explicit and implicit alcohol-related cognition and alcohol use in at-risk adolescents. Psychology of Addictive Behaviors.

Thush, C., Wiers, R.W., Theunissen, N., Van den Bosch, J., Opdenacker, J., Van Empelen, P. et al. (2007). A randomized clinical trial of a targeted intervention to moderate alcohol use and alcohol-related problems in at-risk adolescents. Pharmacology Biochemistry and Behavior, 86, 368 -376.

Thush, C., Wiers, R.W., Ames, S.L., Grenard, J.L., Sussman, S., \& Stacy, A.W. (2008). Interactions between implicit cognition and working memory in the prediction of.alcohol use in at-risk adolescents. Drug and Alcohol Dependence, 94, 116- 124 .

Towles-Schwen, T, \& Fazio, R.H. (2006). Automatically activated racial attitudes as predictors of the success of interracial roommate relationships. Journal of Experimental Social Psychology, 42, 698-705.

Van Dalen, W.E. (1999). "Drank maakt meer kapot dan je lief is". Een beschrijving van het 12,5 jaar bestaan van een unieke campagne. In: Handboek verslaving (pp. C2O5O-1 - C2O5O-21). Utrecht: Trimbos instituut.

Van de Luitgaarden, J., Thush, C., Wiers, R.W., \& Knibbe, R.A. (2008). Prevention of alcohol problems in Dutch youth: Missed opportunities and new developments. Evaluation Q the Health Professions, 31, 167-181.

Van de Luitgaarden, J., Wiers, R.W., Knibbe, R.A. \& Boon, B.J. (2006). From the laboratory to real life: A pilot study of an expectancy challenge with 'heavy drinking' young people on holiday. Substance Use and Misuse, 41, 353-368. 
Van de Luitgaarden, J., Wiers, R.W., Knibbe, R.A., \& Candel, M.J.J.M. (2007). single-session Expectancy Challenge with young heavy drinkers on holiday. Addictive Behaviors, 32, 2865-2878.

Van Dijck, D. \& Knibbe, R.A. (2005). De prevalentie van probleemdrinken in Nederland. Maastricht: Universiteit Maastricht.

Van Kleef, L.E. \& Van der Lely, N. (2006). Jongeren met alcoholintoxicatie: een groeiend probleem. Nederlands Tijdschrift voor Geneeskunde, 150 (46), 2521-2522.

White, A.M., Ghia, A.J., Levin, E.D., \& Swartzwelder H.S. (2000). Binge pattern alcohol exposure: Differential impact on subsequent responsiveness to alcohol. Alcoholism: Clinical and Experimental Research, 24, 1251-1256.

White, A.M., \& Swartzwelder, H.S. (2004). Hippocampal function during adolescence: A unique target of ethanol effects. Annals of the New York Academy of Sciences, 102, 206-220.

Wiers, R.W., Bartholow, B.D., Van den Wildenberg, E., Thush C., Engels, R., Sher, K.J., Grenard, J.L., Ames, S.L, Stacy, \& A.W. (2007). Automatic and controlled processes and the development of addictive behaviors in adolescents: A review and a model. Pharmacology, Biochemistry and Behavior, 86, 263-283.
Wiers, R.W., Cox, W.M., Field, M., Fadardi, J.S., Palfai, T.P., Schoenmakers, T. et al. (2006). The search for new ways to change implicit alcohol-related cognitions in heavy drinkers. Alcoholism: Clinical and Experimental Research, 30, 320-331.

Wiers, R.W., \& Stacy, A.W. (Eds.), (2006). Handbook of implicit cognition and addiction. Thousand Oaks: SAGE.

Wiers, R.W., Van de Luitgaarden, J., Van den Wildenberg, E., \& Smulders, F.T.Y.(2005). Challenging implicit and explicit alcoholrelated cognitions in young heavy drinkers. Addiction, 100, 806-819.

Wilson, S. J., Sayette, M. A., \& Fiez, J. A., (2004). Prefrontal responses to drug cues: A neurocognitive analysis. Nature Neuroscience, 1, 211-214

Wood, M., Capone, C., Laforge, R., Erickson, D.J. \& Brand, N.H. (2007) Brief motivational interview and alcohol expectancy challenge with heavy drinking college students: A randomized factorial study. Addictive Behaviors, 32, 2509-2528. 